Research Paper

\title{
Decreases in Paraoxonase-1 Activities Promote a Pro-inflammatory Effect of Lipids Peroxidation Products in Non-smoking and Smoking Patients with Acute Pancreatitis
}

\author{
Grzegorz Marek ${ }^{1}$, Milena Ściskalska ${ }^{\circledR}$, Zygmunt Grzebieniak$^{1}$, Halina Milnerowicz ${ }^{2}$ \\ 1. Second Department of General and Oncological Surgery, Wroclaw Medical University, Wroclaw, Poland. \\ 2. Department of Biomedical and Environmental Analyses, Faculty of Pharmacy, Wroclaw Medical University, Wroclaw, Poland. \\ $\triangle$ Corresponding authors: Milena Ściskalska, PhD, Department of Biomedical and Environmental Analyses, Faculty of Pharmacy, Wroclaw Medical University, \\ 211 Borowska St., 50-556 Wrocław, Poland; fax: +48 7178401 72, e-mail: milena.topola@wp.pl, ORCID ID: 0000-0001-8976-6683 Or Halina Milnerowicz, \\ Professor, PhD., ScD., Department of Biomedical and Environmental Analyses, Faculty of Pharmacy, Wroclaw Medical University, 211 Borowska St., $50-556$ \\ Wrocław, Poland; fax: +48 7178401 72, e-mail: halina.milnerowicz@umed.wroc.pl, ORCID ID: 0000-0002-0772-9852
}

(c) Ivyspring International Publisher. This is an open access article distributed under the terms of the Creative Commons Attribution (CC BY-NC) license (https://creativecommons.org/licenses/by-nc/4.0/). See http://ivyspring.com/terms for full terms and conditions.

Received: 2018.06.04; Accepted: 2018.09.14; Published: 2018.10.20

\begin{abstract}
Aim: The study investigated the extent to which tobacco smoke exposure causes changes in lipids biochemistry through measurement blood concentrations of: paraoxonase-1 (PON-1) activities as lipid-bound enzyme into cell membrane, concentration of malonyldialdehyde (MDA), protein adducts of 4-hydroxynonenal (HNE-adducts), oxidized low density lipoproteins (oxLDL), total cholesterol $(\mathrm{CH})$ and high-density lipoprotein cholesterol (HDL). Additionally, the activity of $\mathrm{P}$ isoform of glutathione S-transferase (GST- $\Pi$ ) was measured.

Methods: Investigations were performed in the blood of patients with acute pancreatitis (AP) on the $1^{\text {st }}, 3^{\text {rd }}$ and $7^{\text {th }}$ day of hospitalization and in healthy volunteers. The activities of PON-1 forms, GST-ח were determined spectrophotometrically. Concentrations of PON-1, MDA, HNE-adducts, oxLDL, HDL, $\mathrm{CH}$ were measured using commercial tests.

Results: Near 2-fold higher concentrations of MDA, HNE-adducts, oxLDL, correlating with inflammatory markers in AP patients compared to healthy subjects were demonstrated, which were accompanied by gradually increasing $\mathrm{CH} / \mathrm{HDL}$ ratio during hospitalization. During hospital treatment, decreased activities of all PON-1 subtypes were observed in AP patients compared to healthy subjects, more pronounced in tobacco smokers. A decreased PON-1 phosphotriesterase activity in non-AP control group smokers compared to non-smokers was noted. In non-smoking AP patients GST-ח activity normalized during hospitalization in contrast to smokers.

Conclusions: GST- $\Pi$ and PON-1 phosphotriesterase activities seem to be a sensitive marker of pro/antioxidative imbalance in smokers. Lipids peroxidation products generated during AP can intensify preexisting inflammation. Increasing stay in the hospital was associated with worsening of lipids peroxidation markers and the parameters of lipid profile, in both non-smoking and smoking AP patients, what can indicate that the oxidative-inflammatory process are not extinguished.
\end{abstract}

Key words: acute pancreatitis; GST-п; malonylodialdehyde; paraoxonase-1; smoking.

\section{Introduction}

Acute pancreatitis (AP) is one of major causes of hospital admissions for gastrointestinal diseases in many countries. The molecular and biochemical pathomechanism of AP has not been fully understood [1]. It is believed that the primary mechanism of pathogenesis of acute pancreatitis lies in the 
intracellular activation of proenzymes in the exocrine cells of the pancreas, which subsequently results in disruption of the compartmentalization of alveolar cells and self-digestion of the organ [2]. There is also an important role played in the activation of pancreatic enzymes by $\mathrm{Ca}^{2+}$ ions. Destruction of pancreatic acinar cells activates chemotaxis of leukocytes and macrophages, which leads to local and subsequent to systemic inflammatory response [3-5]. Acute inflammation of the pancreatic tissue results in a clinical spectrum ranging from mild and self-limiting to severe, progressing disease associated with high risk of mortality [6].

Tobacco smoke exposure is one of many major factors in the pathogenesis of inflammatory diseases, including acute pancreatitis and was associated with worse AP course [6,7]. Recent evidence has indicated that smoking can be considered as an independent risk factor for AP [6]. Tobacco smoke is a composite mixture of different substances with toxic potential (with prooxidative, proinflammatory, carcinogenic, mutagenic and teratogenic effect) on human cells $[8,9]$. Xenobiotics and free radicals from the smoke are responsible for activation of pro-inflammatory pathways leading to the release of inflammatory mediators $[8,10]$.

The first line of cellular defense against free radicals is cell membrane. Free radicals produced as a result of tobacco smoke exposure can interact with molecules incorporated within cellular membrane. Oxidative damage to the membrane phospholipids initiates lipid peroxidation $[11,12]$. This process generates a variety of $\alpha$ - and $\beta$-unsaturated reactive aldehydes, among others malondialdehyde (MDA) and 4-hydroxynonenal (4-HNE). It contributes to oxidative modification of physiological molecules, such as low density lipoproteins (LDL) turning them into oxidized form - oxLDLs. Products of lipid peroxidation may in turn lead to damage of membrane integrity, inactivation of membrane-bound receptors and enzymes, resulting in cell damage [13]. These lipid peroxidation products, especially 4-HNE, react with proteins, changing their conformation and function, leading to enhanced inflammatory response [14].

Peroxidation of lipids can be limited by the activity of paraoxonase-1 (PON-1) [15-17]. PON-1 is a HDL-bound and calcium-dependent extracellular hydrolase [18-21], produced in the liver and secreted into the bloodstream [11]. This enzyme has the ability to delay or inhibit the initiation of lipoproteins oxidation induced by metal ions and to hydrolyse preformed lipid hydroperoxides [20,21]. The hydrolytic activity of PON-1 on different substrates occurs in three types of enzymatic action: as phosphotriesterase (paraoxonase) (EC 3.1.8.1), as arylesterase (EC 3.1.1.2) and as lactonase (EC 3.1.1.81) [22]. PON-1 was observed as an important endogenous free radical scavenging system in the human body [23]. The activity of this enzyme was shown to be modulated under oxidative stress conditions, such as exposure to tobacco smoke xenobiotics [18]. It was also recognized as an agent modulating antioxidative and anti-inflammatory role of HDL [19-21]. Due to its potential ability to hydrolyse proinflammatory mediator-plateletactivating factor (PAF), PON-1 may exert anti-inflammatory effects $[15,24]$.

Enhanced oxidative stress through inflammation and/or cigarette smoking exposure usually activates intracellular antioxidant defenses as an adaptive response to free radicals action. Important enzymes, which take part in antioxidative defense are glutathione $\mathrm{S}$ transferases (GST, EC 2.5.1.18), including $\mathrm{Pi}$ isoform of GST (GST-ח). GST-п is responsible for detoxification of tobacco smoke constituents and protection against smoking-induced oxidative damage [25]. It is a typical isozyme in erythrocytes, for which a role in Cd accumulation as a major constituent of the smoke was shown [26]. It was suggested that GST-п could have an influence on cellular redox status through the suppression of the production of superoxide anions and peroxides [26].

Closely associated with the inflammatory process are free radicals [11]. Pro/antioxidative imbalance induced by smoke xenobiotics is involved in the pathogenesis of among others acute pancreatitis $[6,27]$. It was also shown that oxidative conditions can exert changes in the lipid profile in the blood and impair HDL-associated antioxidant defense [28]. Our study was aimed to demonstrate the extent to which tobacco smoke exposure is associated with the changes in lipids through assessment of their blood concentrations in healthy volunteers and patients with AP exposed to tobacco smoke xenobiotics: the concentration of MDA, HNE-adducts with proteins, oxLDL, HDL, total cholesterol, the value of Castelli index 1 . The study was also aimed to evaluate the concentration of PON-1 and its phosphotriesterase, arylesterase and lactonase activities as lipid-bound enzymes within the cell membrane. The activity of GST-ח as an enzyme responsible for detoxification of smoke xenobiotics in the study population was also determined.

\section{Materials and Methods}

\section{Materials}

The study group consisted of 46 patients with the diagnosis of AP (22 non-smokers and 24 smokers), 
hospitalized in the Second Clinic of General and Oncological Surgery of Wroclaw Medical University Hospital in years 2014-2016 and 95 healthy volunteers (72 non-smokers and 23 smokers). The study protocol was approved by Local Bioethics Committee of Wroclaw University of Medicine (No: KB-592/2013). The study inclusion criteria are presented in Figure 1.

The volunteers were included based on the research conducted by primary care physicians.
Exclusion criteria from the study group were as follows: presence of co-morbidities, such as neoplastic disease, diabetes, liver disease, ongoing inflammatory states other than AP as well as present or past alcohol and drugs abuse. To confirm the lack of alcohol abuse, carbohydrate-deficient transferrin (CDT) (CEofix CDT kit for Beckman Coulter P/ACE MDQ Series; Ref. No.: 844111036), a biomarker for long-term alcohol consumption, was measured.

\section{Personal interview and clinical symptoms}

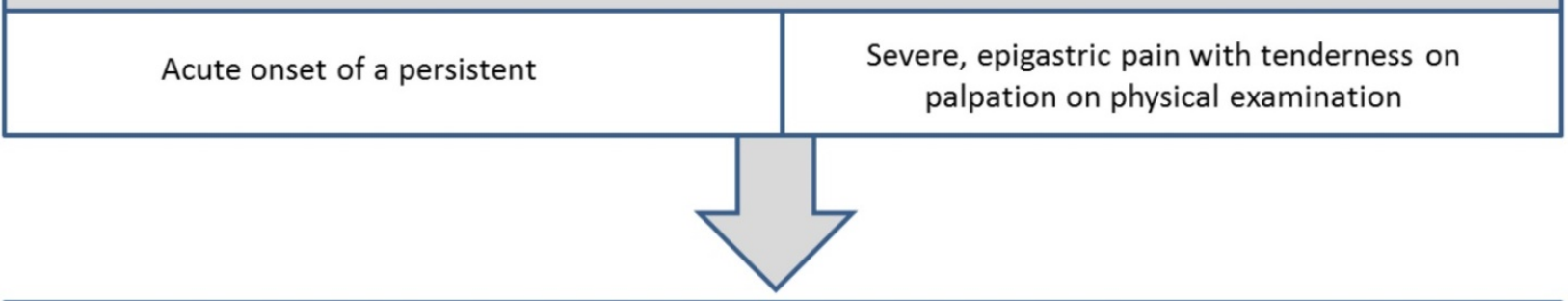

\section{Laboratory tests}

Serum amylase or lipase levels elevated to three times or greater than the upper limit of normal

\begin{tabular}{|c|c|}
\hline \multicolumn{2}{|c|}{$\begin{array}{c}\text { Imaging (contrast-enhanced computed tomography (CT), magnetic resonance } \\
\text { imaging (MRI) or transabdominal ultrasonography) }\end{array}$} \\
\hline $\begin{array}{l}\text { A contrast-enhanced abdominal CT scan: } \\
\text {-The patients with abdominal pain that were not } \\
\text { characteristic for AP } \\
\text {-Serum amylase or lipase levels that were less } \\
\text { than three times the upper limit of normal } \\
\text { - The diagnosis was uncertain }\end{array}$ & $\begin{array}{l}\text { Abdominal MRI without gadolinium: } \\
\text { - The patients with severe contrast allergy or } \\
\text { renal failure }\end{array}$ \\
\hline Intravenous fluid & Treatment \\
\hline $\begin{array}{l}\text { Approximately } 4 \text { liters of crystalloid solutions under } \\
\text { the control of RR/HR, hematocrit, hourly diuresis, } \\
\text { which were modified relative to the dose of } \\
\text { intravenous fluids (5-10 } \mathrm{mL} / \mathrm{kg} / \mathrm{h}) \text { and } \\
\text { a degree of hydration considering the signs fluid } \\
\text { overload and edema }\end{array}$ & $\begin{array}{l}\text { - Any preventive antibiotics } \\
\text { - Oral low-fat diet } \\
\text { - Analgesics (if necessary) : paracetamol, } \\
\text { metamizol, ketoprofen }\end{array}$ \\
\hline
\end{tabular}

Figure 1. Criteria for the inclusion the patients to the study. 
All hospitalized patients and healthy volunteers had received full and thorough information about the study and gave the informed consent in writing. Lifestyle data were gathered in the form of a medical interview and survey. Participants were asked about their health and nutritional habits, use of dietary supplements/medications, frequency of alcohol intake and smoking history. Smoking status was categorized as non-smokers and smokers based on the interview, but it was also verified by determination of serum cotinine concentrations, a metabolite of nicotine. Patients and healthy subjects were considered smokers when cotinine concentration was greater or equal than $15 \mathrm{ng} / \mathrm{ml}$ and non-smokers with cotinine concentration lesser than $15 \mathrm{ng} / \mathrm{ml}$; The interview acquired data on the intensity of smoking was expressed in pack-years, defined as the number of smoked cigarettes per day multiplied by the number of years of smoking divided by 20 (assuming 20 cigarettes in a pack). Body mass index (BMI) was calculated as weight $[\mathrm{kg}] /(\text { height }[\mathrm{m}])^{2}$. Clinical characteristics of the study population were presented in Table 1.

\section{Sample preparation}

The biochemical analyses were performed in serum, plasma and erythrocyte lysate collected from patients with AP and healthy volunteers. Venous blood was collected in the morning, after 12-h fasting. The blood samples from hospitalized patients were collected on their $1^{\text {st }}, 3^{\text {rd }}$ and $7^{\text {th }}$ day of treatment. Serum was obtained according to the standard procedure by taking venous blood for disposable trace-element-free tubes (Cat. No.: 368815, Becton Dickinson, Germany) with serum clotting activator, left at $25^{\circ} \mathrm{C}$ to complete thrombosis, and centrifuged $(1200 \mathrm{~g} / 20 \mathrm{~min})$. In order to obtain plasma and erythrocyte lysate, whole blood was drawn into tubes containing heparin (Cat. No.: 368886, Becton Dickinson, Germany) and centrifuged $(2,500 \mathrm{~g} / 15$ $\mathrm{min}$ ) to separate the plasma and buffy coat from erythrocyte pellet. The erythrocytes were then directly transferred to other tubes to prevent hemolysis. The erythrocyte pellet was washed twice in an equal volume of ice-cold $0.9 \% \mathrm{NaCl}$. The washed cells were lysed by addition of ice-cold double distilled water (1:1.4). The resulting lysate was used for the assays. The obtained samples of serum, plasma and erythrocyte lysate were portioned and stored in sealed tubes (Cat. No.: 0030102.002, Eppendorf, Germany). The samples were stored at $-80^{\circ} \mathrm{C}$ until analysis.

\section{Methods}

Cotinine concentration in serum was measured with the use of commercial Cotinine ELISA test (Cat. No.: EIA-3242, DRG International, Inc., USA). It provides qualitative screening results for cotinine in human serum at a cut-off concentration of $15 \mathrm{ng} / \mathrm{mL}$.

High-sensitivity CRP (hsCRP) concentration was determined in serum by turbidimetric method using C-reactive protein hs test (Cat. No.: 31927, Biosystems, Spain).

Table 1. Clinical characteristics of the participants in the study.

\begin{tabular}{|c|c|c|}
\hline Parameters & $\begin{array}{l}\text { Non-smokers } \\
\text { Mean } \pm \text { SD }\end{array}$ & $\begin{array}{l}\text { Smokers } \\
\text { Mean } \pm \text { SD }\end{array}$ \\
\hline \multicolumn{3}{|l|}{ Healthy subjects } \\
\hline Age [years] & $24.3 \pm 5.4$ & $23.4 \pm 2.4$ \\
\hline BMI $\left[\mathrm{kg} / \mathrm{m}^{2}\right]$ & $22.2 \pm 2.8$ & $22.6 \pm 3.0$ \\
\hline $\mathrm{hsCRP}[\mathrm{mg} / \mathrm{l}]$ & $0.2 \pm 0.1$ & $3.3 \pm 2.8^{1)}$ \\
\hline Pack years of smoking & NA & $3.5 \pm 2.6$ \\
\hline Cotinine $[\mathrm{ng} / \mathrm{ml}]$ & $1.6 \pm 2.1$ & $79.5 \pm 40.1^{1)}$ \\
\hline \multicolumn{3}{|l|}{ Patients with AP } \\
\hline Age [years] & $50.0 \pm 19.5^{1)}$ & $45.8 \pm 13.1^{2)}$ \\
\hline BMI $\left[\mathrm{kg} / \mathrm{m}^{2}\right]$ & $27.3 \pm 4.7^{1)}$ & $23.9 \pm 4.2$ \\
\hline $\begin{array}{l}\text { The number of AP attacks in the } \\
\text { past }\end{array}$ & $1-3$ & $2-10$ \\
\hline Ranson Criteria [score] & $2.5 \pm 0.9$ & $2.5 \pm 0.7$ \\
\hline hsCRP [mg/l] & $167.7 \pm 54.1^{1)}$ & $136.5 \pm 74.8^{2)}$ \\
\hline Leukocytes $\left[10^{9} / 1\right]$ & $11.3 \pm 4.7$ & $9.8 \pm 5.3$ \\
\hline Erythrocytes $\left[10^{12} / 1\right]$ & $4.1 \pm 0.9$ & $4.0 \pm 0.7$ \\
\hline Hemoglobin [g/dl] & $12.2 \pm 2.4$ & $11.9 \pm 1.9$ \\
\hline Hematocrit [\%] & $36.4 \pm 6.2$ & $35.4 \pm 4.4$ \\
\hline Bilirubin (total) [mg/dl] & $0.9 \pm 0.6$ & $1.2 \pm 0.6$ \\
\hline ALAT [U/1] & $23.4 \pm 17.5$ & $37.3 \pm 35.1$ \\
\hline ASPAT [U/1] & $30.9 \pm 15.7$ & $38.6 \pm 27.2$ \\
\hline Alkaline phosphatase [U/1] & $143.3 \pm 104.4$ & $135.1 \pm 75.3$ \\
\hline Lipase [U/1] & $465.7 \pm 668.5$ & $355.8 \pm 476.1$ \\
\hline Glucose [mg/dl] & $104.5 \pm 22.9$ & $116.8 \pm 27.2$ \\
\hline Urea [mg/dl] & $18.3 \pm 8.9$ & $29.4 \pm 17.9^{3)}$ \\
\hline Creatinine $[\mathrm{mg} / \mathrm{dl}]$ & $1.0 \pm 0.8$ & $1.4 \pm 1.7$ \\
\hline Pack years of smoking & NA & $23.0 \pm 18.6^{2)}$ \\
\hline Cotinine $[\mathrm{ng} / \mathrm{ml}]$ & $0.9 \pm 0.8$ & $\begin{array}{l}142.5 \pm 48.92) \\
\text { 3) }\end{array}$ \\
\hline
\end{tabular}

NA-not applicable

1) $\mathrm{p}<0.05$ compared to non-smoking healthy subjects

${ }^{2)} \mathrm{p}<0.05$ compared to smoking healthy subjects

3) $\mathrm{p}<0.05$ compared to non-smoking $\mathrm{AP}$ patients

MDA concentration in plasma was determined by colorimetric method using Lipid Peroxidation (MDA) Assay Kit (Cat. No. MAK085-1KT, Sigma-Aldrich, Germany).

HNE-adducts concentration in serum was measured with the use of commercial test OxiSelect HNE Adduct Competitive ELISA Kit (Cat. No.: STA-838, Cell Biolabs, USA).

To determinate the level of oxLDL in serum, the commercial Mercodia Oxidised LDL ELISA kit was used (Cat.: No.: 10-1143-01, Mercodia, Sweden).

HDL concentration in serum was determined using a direct method with the commercial test (Cat. No.: 10300060, BioMaxima, Poland). HDL was subjected to enzymatic reaction which resulted in the formation of color compounds. The amount of color 
product was proportional to the HDL concentration in the sample. The absorbance was measured at $\lambda=600$ $\mathrm{nm}$ at $25^{\circ} \mathrm{C}$.

Total cholesterol $(\mathrm{CH}$ total $)$ in serum was measured using a reagent for the quantitative determination of total cholesterol (Cat. No.: 5017.1; BioMaxima, Poland). Cholesterol was measured enzymatically according to the procedure described in technical bulletin provided by the manufacturer. The color intensity was proportional to cholesterol concentration. Absorbance was measured at $\lambda=500$ $\mathrm{nm}$ at $25^{\circ} \mathrm{C}$.

The ratio $\mathrm{CH}$ total concentration/HDL concentration was expressed as Castelli Index 1 [29].

Phosphotriesterase activity of PON-1 (PON-1(P)) was measured in fresh serum according to the spectrophotometric method described by Bizon et al. [18]. The method utilizes the ability of PON-1 to split ester linkages in paraoxon (Cat. No.: 311-45-5; Sigma-Aldrich, Germany) at $37^{\circ} \mathrm{C}$ in a $100 \mathrm{mM}$ Tris- $\mathrm{HCl}$ buffer ( $\mathrm{pH}$ 8.5) containing $2 \mathrm{mM} \mathrm{CaCl}_{2}$. As a result, p-nitrophenol is formed, the amount of which is proportional to the change in absorbance over time at $\lambda=405 \mathrm{~nm}$. The amount of 4-nitrophenol produced was then calculated from the molar extinction coefficient of $18.053(\mu \mathrm{mol} / \mathrm{L})^{-1} \mathrm{~cm}^{-1}$. One unit of PON-1(P) activity was expressed as $1 \mu \mathrm{mol}$ of paraoxon hydrolyzed per minute at a temperature of $37^{\circ} \mathrm{C}$.

Arylesterase activity of PON-1 (PON-1(A)) was determined in fresh serum by the process described earlier by Eckerson et al. [30] and Lixandru et al. [31] with own modifications. The method utilises phenyl acetate (Cat. No.: 122-79-2; Sigma Aldrich, Germany) as a substrate at $37^{\circ} \mathrm{C}$ in a $20 \mathrm{mM}$ Tris- $\mathrm{HCl}$ buffer (pH 8.0) containing $1 \mathrm{mM} \mathrm{CaCl}$. As the effect of phenyl acetate hydrolysis, phenol was formed, what resulted in a change in absorbance at $\lambda=270 \mathrm{~nm}$ over time. The amount of produced phenol was calculated from the molar extinction coefficient of $1310(\mathrm{~mol} / \mathrm{L})^{-1}$ $\mathrm{cm}^{-1}$. One unit of PON-1(A) activity was expressed as $1 \mu \mathrm{mol}$ of phenyl acetate hydrolyzed per minute at a temperature of $37^{\circ} \mathrm{C}$.

Lactonase activity of PON-1 (PON-1(L)) was determined in fresh serum by modified method described previously by Kataoka et al. [32]. The method uses dihydrocoumarin (Cat. No.: 119-84-6; Sigma-Aldrich, Germany) as a substrate at $37^{\circ} \mathrm{C}$ in a $50 \mathrm{mM}$ Tris- $\mathrm{HCl}$ buffer ( $\mathrm{pH} 7.0$ ) containing $1 \mathrm{mM}$ $\mathrm{CaCl}_{2}$. As the effect of dihydrocoumarin hydrolysis, 3-(2-hydroxyphenyl)propionate was formed, which resulted in a change in absorbance over time at $\lambda=270$ $\mathrm{nm}$. The amount of produced 3-(2-hydroxyphenyl) propionate was calculated from the molar extinction coefficient of $1870(\mathrm{~mol} / \mathrm{L})^{-1} \mathrm{~cm}^{-1}$. One unit of
PON-1(L) activity was expressed as $1 \mu \mathrm{mol}$ of dihydrocoumarin hydrolyzed per minute at a temperature of $37^{\circ} \mathrm{C}$.

The changes in absorbance for PON-1 activities (PON-1(P), PON-1(A) and PON-1(L)) were measured at $10 \mathrm{~s}$ intervals for 1-3 min.

The concentration of PON-1 was measured in serum using Paraoxonase 1 Human ELISA kit (Cat. No.: RD191279200R, BioVendor, Czech Republic).

GST-ח activity in erythrocyte lysate was measured spectrophotometrically using ethacrynic acid $(0.2 \mathrm{mM})$ in ethanol as substrate, according to Habig et al. [33]. The assay was conducted at $25^{\circ} \mathrm{C}$ in $100 \mathrm{mM}$ potassium phosphate at $\mathrm{pH}=6.5$ and $5 \mathrm{mM}$ GSH concentration. The change in absorbance was measure at $\lambda=270 \mathrm{~nm}$. One unit of enzyme activity was defined as amount of enzyme catalyzing the conversion of $1 \mu$ mole of substrate per minute at $25^{\circ} \mathrm{C}$. The results of GST-п activity were expressed as U/g hemoglobin.

Hemoglobin concentration in the erythrocyte lysate was measured using Drabkin reagent (Cat. No.: 20082, Aqua-Med, Poland).

The absorbance of samples was measured using a spectrophotometers: Specord 40 (Analytic Jena, DE, Cat. No.: 400280), MultiScan Go (Thermo Scientific, USA, Cat. No.: N10588) and Genesys $10 S$ (Thermo Scientific, USA, Cat. No.: 840-208100).

\section{Statistical analysis}

The data was expressed as mean \pm standard deviation (SD) values. The differences between the examined groups were tested using a 2-way Analysis of Variance (ANOVA) with Tukey's multiple comparison test (the activities of PON-1(P), PON-1(A) and PON-1(L), GST-ח, the concentrations of hsCRP, oxLDL, $\mathrm{CH}, \mathrm{HDL}, \mathrm{PON}-1)$ or a nonparametric Kruskal-Wallis test (the concentrations of cotinine, MDA, HNE-adducts, the value of Castelli Index 1). The normality of the variables was analyzed with use of the Shapiro-Wilk W test. In order to verify correlations between examined parameters, the multiple linear regression models were performed. In all instances, $\mathrm{p}<0.05$ was considered statistically significant. Statistical calculations were done using the Statistica Software Package, version 10.0 (Polish version: StatSoft, Krakow, Poland).

\section{Results}

The effect of tobacco smoke exposure on the concentrations of oxidative stress markers and the values of Castelli-1 index

An increased HNE-adducts concentration in the blood of patients with AP was observed, especially in 
the group of smokers $(p=0.045)$, compared to healthy subjects. It was noted that the level of this parameter was gradually elevating during hospitalization of both, smoking and non-smoking AP patients, but the differences were not statistically significant (Table 2).

It was observed that MDA plasma concentration was significantly higher in smokers compared to non-smokers, in both the patients with AP $(p=0.047)$ and the healthy subjects $(p=0.041)$. Additionally, the concentration of this marker was twice as high in AP patients when compared to appropriate healthy subjects, with significant differences between smokers $(p<0.001)$ and non-smokers $(p<0.001)$, respectively. It was noted that MDA concentration gradually elevated during hospitalization. Values of this parameter in the non-smoking $\mathrm{AP}$ patients were significantly increased by more than $30 \%(p=0.020)$ and $40 \% \quad(p=0.011)$ on the $3^{\text {rd }}$ and $7^{\text {th }}$ day of hospitalization respectively compared to the $1^{\text {st }}$ day. In the group of AP patients who were smokers, blood MDA concentration was higher by $30 \%$ on the $7^{\text {th }}$ day of hospitalization when compared to the $1^{\text {st }}(\mathrm{p}=0.006)$ and $3^{\text {rd }}$ day $(\mathrm{p}=0.041)$ (Table 2).

A higher oxLDL levels in the blood of patients with AP compared to healthy subjects, in both non-smokers $(p=0.028)$ and smokers $(p=0.008)$, were noted. This parameter remained elevated during hospitalization of AP patients (Table 2).

Significant decreases in HDL concentrations in the blood of patients with AP compared to healthy subjects, in both smokers $(\mathrm{p}<0.001)$ and non-smokers $(p<0.001)$ were observed. Additionally, changes in HDL concentrations during hospitalization of AP patients were shown. In the group of non-smoking patients with AP, HDL concentration was lower by half on the $7^{\text {th }}$ day of hospitalization compared to the $1^{\text {st }}$ day $(p=0.004)$. Decreases by $50 \%$ in the HDL concentrations on the $3^{\text {rd }}(p=0.036)$ and the $7^{\text {th }}$ $(p=0.024)$ day of hospitalization compared to day one in the blood of smoking patients with $\mathrm{AP}$ were shown (Table 2).

Table 2. The influence of tobacco smoke exposure to the dynamics of changes in the concentration of lipids peroxidation products (HNE-adducts, oxLDL, MDA) and the parameters of lipids metabolism (HDL, total cholesterol concentration, Castelli index 1) in the blood of patients with AP (in the 1 st, $3^{\text {rd }}$ and $7^{\text {th }}$ day of hospitalization) and healthy subjects.

\begin{tabular}{|c|c|c|c|c|}
\hline & Patients with AP & & Healthy subjects & \\
\hline Parameters & Non-smokers (Mean \pm SD) & Smokers (Mean \pm SD) & Non-smokers (Mean \pm SD) & Smokers (Mean \pm SD) \\
\hline \multicolumn{5}{|c|}{ HNE-adducts [ $\mu \mathrm{g} / \mathrm{ml}]$} \\
\hline $1^{\text {st }}$ day & $18.9 \pm 8.9$ & $22.5 \pm 15.1^{1)}$ & $11.0 \pm 9.0$ & $10.7 \pm 7.4$ \\
\hline $3^{\text {rd }}$ day & $25.2 \pm 14.3$ & $30.7 \pm 13.9$ & & \\
\hline $7^{\text {th }}$ day & $37.0 \pm 23.2$ & $39.5 \pm 31.8$ & & \\
\hline \multicolumn{5}{|c|}{ MDA $[\mathrm{nmol} / \mu \mathrm{l}]$} \\
\hline $1^{\text {st }}$ day & $2.0 \pm 0.3^{2)}$ & $2.5 \pm 0.6^{1), 3)}$ & $1.1 \pm 0.7$ & $1.4 \pm 0.7^{2)}$ \\
\hline $3^{\text {rd }}$ day & $2.8 \pm 0.8^{4)}$ & $2.6 \pm 0.6$ & & \\
\hline $7^{\text {th }}$ day & $3.2 \pm 1.1^{4)}$ & $3.1 \pm 0.5^{4), 5)}$ & & \\
\hline \multicolumn{5}{|l|}{ oxLDL [U/1] } \\
\hline $1^{\text {st }}$ day & $87.7 \pm 43.7^{2)}$ & $97.0 \pm 47.7^{1)}$ & $52.6 \pm 17.6$ & $58.7 \pm 19.3$ \\
\hline $3^{\text {rd }}$ day & $106.5 \pm 33.6$ & $101.4 \pm 36.1$ & & \\
\hline $7^{\text {th }}$ day & $89.4 \pm 55.6$ & $71.1 \pm 22.4$ & & \\
\hline \multicolumn{5}{|c|}{$\mathrm{HDL}[\mathrm{mg} / \mathrm{dl}]$} \\
\hline $1^{\text {st }}$ day & $20.7 \pm 12.3^{2)}$ & $22.4 \pm 12.3^{1)}$ & $50.9 \pm 21.3$ & $47.3 \pm 7.0$ \\
\hline $3^{\text {rd day }}$ & $14.0 \pm 8.0$ & $13.2 \pm 7.3^{4)}$ & & \\
\hline $7^{\text {th }}$ day & $8.5 \pm 6.3^{4)}$ & $11.5 \pm 4.4^{4)}$ & & \\
\hline \multicolumn{5}{|c|}{$\mathrm{CH}$ total $[\mathrm{mg} / \mathrm{dl}]$} \\
\hline $1^{\text {st }}$ day & $129.9 \pm 36.4^{2)}$ & $149.4 \pm 43.3^{1)}$ & $182.5 \pm 37.4$ & $176.1 \pm 24.2$ \\
\hline $3^{\text {rd day }}$ & $138.5 \pm 32.0$ & $137.7 \pm 23.5$ & & \\
\hline $7^{\text {th }}$ day & $126.7 \pm 34.3$ & $138.7 \pm 22.8$ & & \\
\hline \multicolumn{5}{|c|}{ Castelli index 1} \\
\hline $1^{\text {st }}$ day & $5.8 \pm 2.0^{2)}$ & $5.4 \pm 2.6$ & $4.0 \pm 1.9$ & $4.2 \pm 1.8$ \\
\hline $3^{\text {rd }}$ day & $11.9 \pm 7.1^{4)}$ & $9.5 \pm 7.0^{4)}$ & & \\
\hline $7^{\text {th }}$ day & $16.1 \pm 10.6^{4)}$ & $14.1 \pm 9.5^{4)}$ & & \\
\hline
\end{tabular}

1) $\mathrm{p}<0.05$ compared to smoking healthy subjects. ${ }^{2)} \mathrm{p}<0.05$ compared to non-smoking healthy subjects. ${ }^{3)} \mathrm{p}<0.05$ compared to non-smoking AP patients. ${ }^{4)} \mathrm{p}<0.05$ compared to the $1^{\text {st }}$ day of hospitalization. $\left.{ }^{5}\right) \mathrm{p}<0.05$ compared to the $3^{\text {rd }}$ day of hospitalization. 


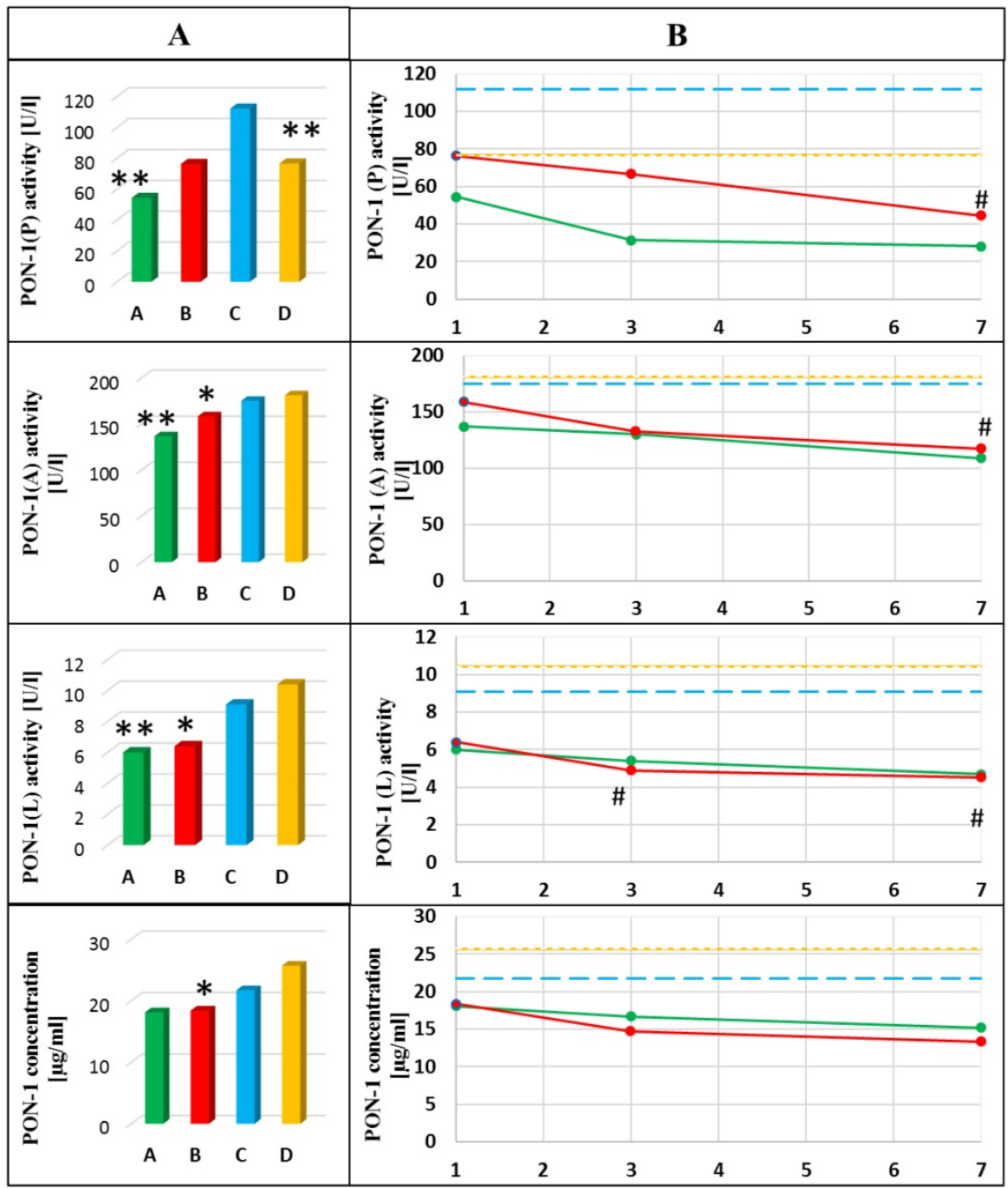

Figure 2. Dynamics of the changes in activities and concentration of PON-1 in the blood of healthy subjects and patients with AP in the 1 st day of hospitalization (A) and next days of hospitalization (B). A- mean value for non-smoking patients with AP; B- mean value for smoking patients with AP; C- mean value for non-smoking healthy subjects; D- mean value for smoking healthy subjects; ${ }^{*} \mathrm{p}<0.05$ compared to smoking healthy subjects; $* * \mathrm{p}<0.05$ compared to non-smoking healthy subjects; \# $p<0.05$ compared to the 1 st day of hospitalization. Green line means value for non-smoking patients with AP; Red line means value for smoking patients with AP; Blue line means value for non-smoking control group; Yellow line means value for smoking control group.

A decrease in total cholesterol $(\mathrm{CH}$ total) concentration in the blood of patients with AP compared to healthy subjects was observed. $\mathrm{CH}$ total concentration was lowered by $30 \%$ in the blood of non-smoking AP patients and by more than $20 \%$ in the blood of smoking AP patients compared to non-smokers $(p<0.001)$ and smokers $(p=0.015)$ of healthy subjects, respectively (Table 2).

Castelli Index 1 in the examined groups was calculated. An increased value of Castelli Index 1 in the group of non-smoking patients with AP compared to healthy non-smokers $(p=0.013)$ was shown. It was shown that the values of this parameter were gradually increasing during hospitalization of both, non-smoking and smoking AP patients. Near 2-fold increase in the value of Castelli index 1 was observed on the $3^{\text {rd }}$ day of hospitalization $(p=0.035$ and $p=0.038$ for non-smokers and smokers, respectively) and more than 2-fold increase on the $7^{\text {th }}$ day of treatment, when compared to the $1^{\text {st }}$ day $(p=0.018$ and $p=0.001$ for non-smokers and smokers, respectively) (Table 2).

The effect of tobacco smoke exposure on the activities and concentration of PON-1 and GST- $-\pi$ activities

The activity of PON-1(P) decreased nearly 2-fold in the blood of non-smoking patients with $\mathrm{AP}$ compared to healthy non-smokers $(p=0.003)$. Additionally, a progressive decrease in the activity of this enzyme in the group of smoking patients with $\mathrm{AP}$ was observed. The activity of PON-1(P) in patients on the $7^{\text {th }}$ day of treatment was nearly 2 -fold lower compared to the one on the $1^{\text {st }}$ day in this group $(p=0.028)$. PON-1(P) was also decreased (by $30 \%$ ) in healthy smokers compared to non-smokers $(p=0.003)$ (Figure 2). 
Significantly lower PON-1(A) activities in the blood of patients with AP compared to healthy subjects, in both smokers $(p=0.031)$ and non-smokers $(p=0.030)$ were observed. Additionally, it was observed that the activity of this enzyme was gradually decreasing during hospitalization of smoking AP patients $(\mathrm{p}=0.047$ for comparison of the $1^{\text {st }}$ and the $7^{\text {th }}$ day) (Figure 2).

A decrease in the activity of PON-1(L) in the blood of AP patients compared to healthy subjects, in both non-smokers $(p=0.001)$ and smokers $(p<0.001)$ was shown. Additionally, it was observed that PON-1(L) activity was continually decreasing during hospitalization of smoking AP patients $(p=0.024$ for comparison of the $1^{\text {st }}$ and the $3^{\text {rd }}$ day of hospitalization and $p=0.033$ for comparison of the $1^{\text {st }}$ and the $7^{\text {th }}$ day of hospitalization) (Figure 2).

A decreased PON-1 concentration in the blood of AP patients, especially in smokers was shown compared to smoking healthy subjects $(\mathrm{p}=0.040)$. The level of this parameter remained unchanged during hospitalization of AP patients (Figure 2).

The analysis of PON-1 activities and the concentration of all subtypes with respect to age and BMI was presented in Figure 3. A decrease in the activities of PON-1(A) and PON-1(L) in the blood of AP patients and healthy was observed in subjects of age $\geq 40$ as compared to those of age $<40$ (PON-1(A): $p=0.033$ in smoking AP patients; PON-1(L): $p=0.049$ and $p=0.041$ in non-smoking and smoking AP patients, respectively; $\mathrm{p}=0.018$ for non-smoking healthy subjects). Similar differences with respect to age groups were noted in PON1 concentration ( $\mathrm{p}=0.016$ in non-smoking AP patients). There were no differences in PON-1 concentration and activity between individuals with BMI $<25$ $\mathrm{kg} / \mathrm{m}^{2}$ compared to those with BMI $\geq 25 \mathrm{~kg} / \mathrm{m}^{2}$ in both groups, patients with AP and healthy subjects (Figure $3)$.

The gradual increase in the activity of GST-ח during hospitalization of non-smoking patients with AP was observed. It was shown that GST-ח activity was higher on the $3^{\text {rd }}$ and the $7^{\text {th }}$ day compared to the $1^{\text {st }}$ day of hospitalization $(p=0.049$ and $p=0.022$, respectively). A significant decrease in the activity of this enzyme in the smoking healthy subjects compared to healthy non-smokers was also observed $(\mathrm{p}=0.005)$ (Figure 4).

Correlation tests between examined parameters were performed. The obtained correlation coefficients between parameters measured in the blood of healthy subjects and patients with AP were presented in Table 3 and Table 4.
Table 3. The correlation coefficients resulted for linear regression performed between the activities of $\mathrm{PON}-1$ and parameters determined in the blood of patients with AP and healthy subjects.

\begin{tabular}{|c|c|c|c|}
\hline Parameters & PON-1(P) & PON-1(A) & PON-1(L) \\
\hline \multicolumn{4}{|c|}{ Non-smoking patients with AP } \\
\hline HDL & $\begin{array}{l}r=0.6326 \\
p=0.050\end{array}$ & $\begin{array}{l}r=0.7176 \\
p=0.045\end{array}$ & NS \\
\hline Castelli index 1 & NS & NS & $\begin{array}{l}r=-0.8163 \\
p=0.048\end{array}$ \\
\hline oxLDL & NS & $\begin{array}{l}r=-0.8901 \\
p=0.043\end{array}$ & $\begin{array}{l}\mathrm{r}=-0.9094 \\
\mathrm{p}=0.032\end{array}$ \\
\hline HNE-adducts & $\begin{array}{l}r=-0.9718 \\
p=0.028\end{array}$ & $\begin{array}{l}r=-0.9061 \\
p=0.034\end{array}$ & $\begin{array}{l}r=-0.9440 \\
p=0.016\end{array}$ \\
\hline \multicolumn{4}{|c|}{ Smoking patients with AP } \\
\hline Age & NS & $\begin{array}{l}r=-0.4927 \\
p=0.032\end{array}$ & $\begin{array}{l}r=-0.5246 \\
p=0.021\end{array}$ \\
\hline HDL & NS & $\begin{array}{l}r=0.4999 \\
p=0.025\end{array}$ & NS \\
\hline Castelli index 1 & NS & NS & $\begin{array}{l}r=-0.5531 \\
p=0.0325\end{array}$ \\
\hline Cotinine & NS & $\begin{array}{l}r=-0.4787 \\
p=0.033\end{array}$ & $\begin{array}{l}\mathrm{r}=-0.5576 \\
\mathrm{p}=0.008\end{array}$ \\
\hline MDA & $\begin{array}{l}r=-0.6030 \\
p=0.038\end{array}$ & $\begin{array}{l}r=-0.4980 \\
p=0.035\end{array}$ & $\begin{array}{l}\mathrm{r}=-0.5525 \\
\mathrm{p}=0.017\end{array}$ \\
\hline \multicolumn{4}{|c|}{ Smoking healthy subjects } \\
\hline MDA & $\begin{array}{l}r=-0.5290 \\
p=0.024\end{array}$ & $\begin{array}{l}r=-0.4845 \\
p=0.042\end{array}$ & $\begin{array}{l}r=-0.4823 \\
p=0.036\end{array}$ \\
\hline
\end{tabular}

NS - not statistically significant.

HDL - high density lipoprotein; HNE-adducts - protein adducts of

8-hydroxynonenal; MDA - malonylodialdehyde; oxLDL - oxidized low density lipoproteins; PON-1(P) - phosphotriesterase activity of paraoxonase-1; PON-1(A) arylesterase activity of paraoxonase-1; PON-1(L) - lactonase activity of paraoxonase-1.

Table 4. The correlation coefficients resulted for linear regression performed between oxidative stress markers and parameters determined in the blood of patients with AP and healthy subjects.

\begin{tabular}{|c|c|c|}
\hline Correlations & $\mathrm{r}$ & $\mathrm{p}$ \\
\hline \multicolumn{3}{|c|}{ Non-smoking patients with AP } \\
\hline MDA - GST-п & -0.9658 & $p<0.001$ \\
\hline MDA - HDL & -0.8920 & 0.042 \\
\hline MDA - hsCRP & 0.9031 & 0.014 \\
\hline Castelli index 1 - hsCRP & 0.8978 & 0.015 \\
\hline Castelli index 1 - Ranson score & 0.7549 & 0.030 \\
\hline \multicolumn{3}{|c|}{ Smoking patients with AP } \\
\hline Age - PON-1 concentration & -0.7117 & 0.016 \\
\hline Cotinine - MDA & 0.5764 & 0.012 \\
\hline Cotinine - HDL & -0.5605 & 0.016 \\
\hline MDA - HDL & -0.6227 & 0.008 \\
\hline MDA - Castelli index 1 & 0.5898 & 0.034 \\
\hline HNE-adducts - hsCRP & -0.6332 & 0.049 \\
\hline \multicolumn{3}{|c|}{ Non-smoking healthy subjects } \\
\hline oxLDL - Castelli 1 index & -0.6466 & 0.043 \\
\hline \multicolumn{3}{|c|}{ Smoking healthy subjects } \\
\hline $\mathrm{HNE}$ adducts - $\mathrm{CH}$ total & -0.6962 & 0.002 \\
\hline
\end{tabular}

CH total - total cholesterol; GST-ח - P isoform of glutathione S transferase; HDL high density lipoprotein; hsCRP - high sensitive C-reactive protein; MDA -

malonylodialdehyde; HNE-adducts - protein adducts of 8-hydroxynonenal; oxLDL - oxidized low density lipoproteins. 


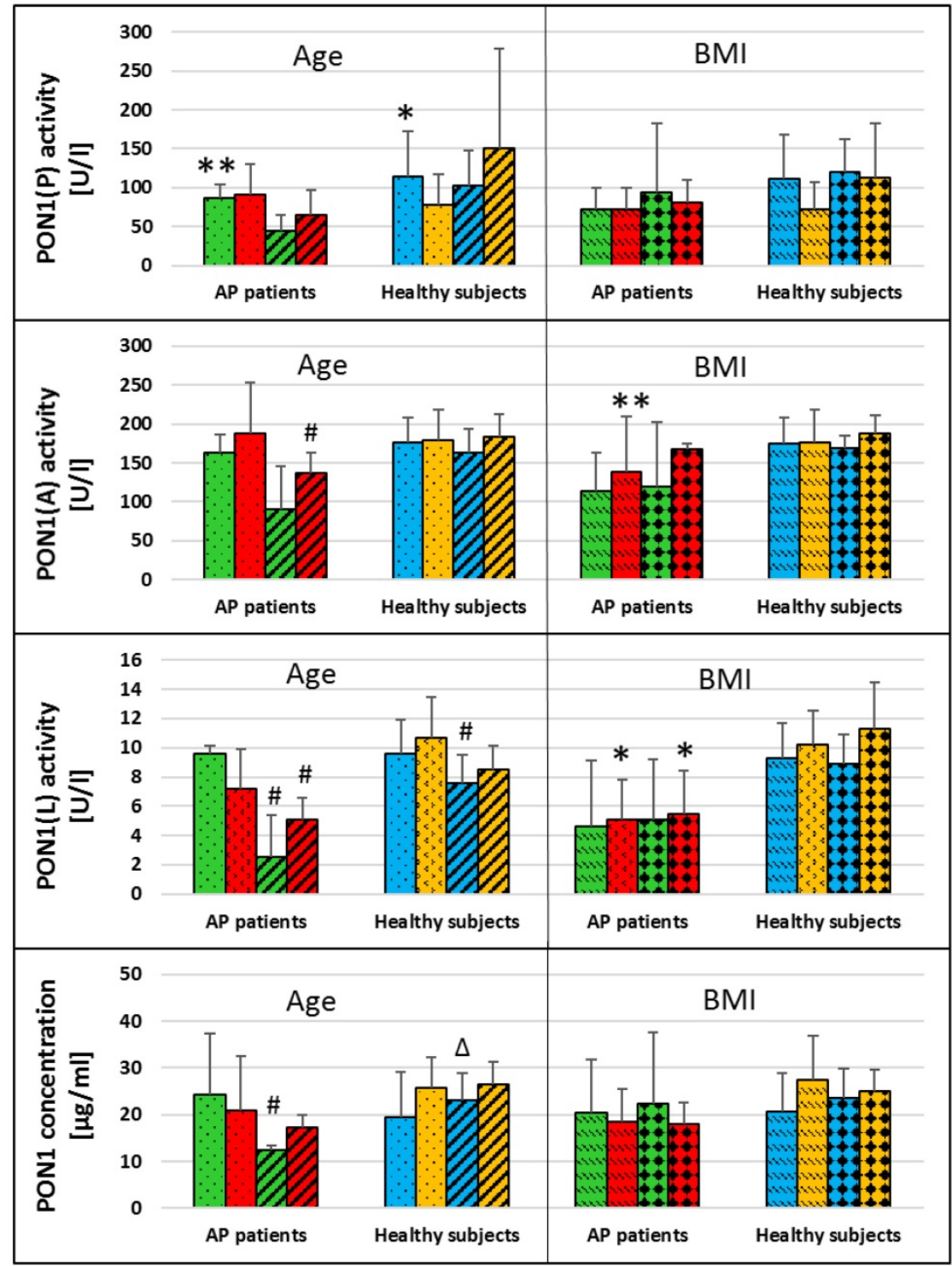

Non-smoking AP patients
Smoking AP patients
Non-smoking healthy subjects Individuals in age $\leq 40$
Smoking healthy subjects

Figure 3. Mean $( \pm S D)$ values of PON-1 activities and PON1 concentrations in the blood of non-smoking and smoking healthy subjects and patients with AP divided in terms of age and BMI. ${ }^{*}<0.05$ compared to smoking healthy subjects; ${ }^{*}{ }^{*}<0.05$ compared to non-smoking healthy subjects; \# $p<0.05$ compared to subjects in age $\leq 40 ; \Delta p<0.05$ compared to non-smoking AP patients

\section{Discussion}

Oxidative stress implicated in the pathogenesis of acute pancreatitis can intensify the damage of pancreatic tissue [34]. Additionally, oxidative stress induced by the smoke can activate a pro-inflammatory cascade, what intensifies a preexisting inflammation [9]. Results of this study confirm that AP is associated with generation of strong oxidative stress, gradually increasing during hospitalization of the patients. It leads to intensified lipid peroxidation, what was reflected in elevated MDA concentration and the lack of normalization in HNE-adducts and oxLDL levels in the blood of both, smoking and non-smoking AP patients. These results confirm rather intuitive thesis that the course of AP is more potent inducer of oxidative stress in comparison to exposure to tobacco smoke xenobiotics. 


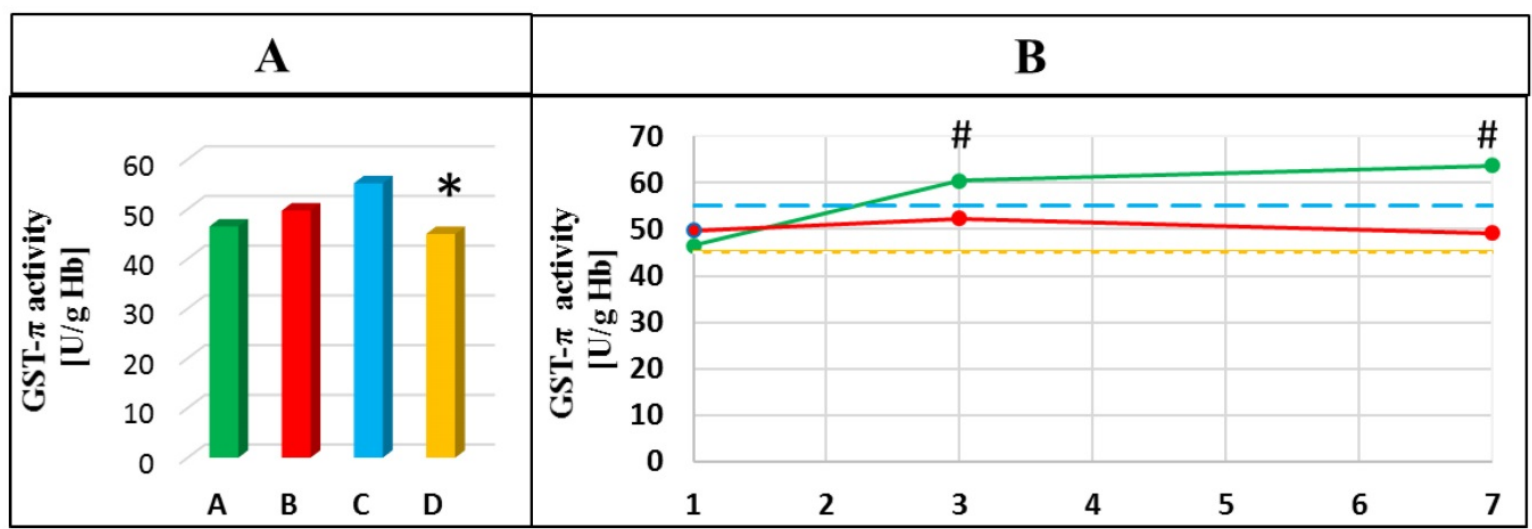

Figure 4. Dynamics of the changes in GST- $\Pi$ activities in the blood of healthy subjects and patients with AP in the 1 st day of hospitalization (A) and next days of hospitalization (B). A- mean value for non-smoking patients with AP; B- mean value for smoking patients with AP; C- mean value for non-smoking healthy subjects; Dmean value for smoking healthy subjects; ${ }^{*} p<0.05$ compared to non-smoking healthy subjects; \# $p<0.05$ compared to the 1 st day of hospitalization. Green line means value for non-smoking patients with AP; Red line means value for smoking patients with AP; Blue line means value for non-smoking control group; Yellow line means value for smoking control group.

Enhanced oxidative stress induced by smoking and inflammatory mechanisms of AP may interfere with membrane-linked antioxidants, such as PON-1 $[35,36]$. PON-1 associated with HDL molecule is able to hydrolyze hydrogen peroxide, which is a major form of reactive oxygen produced during oxidative stress [37]. On the other hand, studies conducted in vitro showed that this enzyme can be easily inactivated by hydroxyl radicals [38]. In our study, a decrease in PON-1(P), PON-1(A) and PON-1(L) activities in $\mathrm{AP}$ in comparison to healthy subjects was demonstrated, what is consistent with observations by other authors $[11,28,39]$. Simultaneous decrease in PON-1 activities, negatively correlating with levels of lipids peroxidation markers can indicate that lipid peroxidation products can affect PON-1 structure and inhibit its activity. Other research showed that lipids peroxidation products can form adducts with highly nucleophilic sulfhydryl thiolate groups on cysteine, lysine and histidine residues, what can modify reactivity of membrane proteins [40].

To explain pathomechanism of changes in PON-1 activities, the concentration PON-1, HDL and total cholesterol were determined. Reduced PON-1 activities in AP patients compared to healthy subjects, accompanied by decreased PON-1 concentration in smokers, can indicate disorders in hepatic synthesis of this enzyme in this group. Additionally, analysis of PON-1 concentrations/activities with respect to age and BMI, as factors that can affect PON-1 synthesis, showed an inverse relation of these parameters to age in the group of AP patients. It remains in accordance with the results of the study conducted by Kumar et al., in which a strong relation of age and PON-1 activity was shown [41]. It was noted that age was strongly related to the increase of blood level of lipid peroxidation markers, which could impair PON-1 function as antioxidant or its synthesis dependent on lipoprotein metabolism [41]. There is evidence that the PON-1 activity/concentration is an adjunctive marker of altered lipoprotein metabolism as protein affects the process of cholesterol efflux [41].

The changes in PON-1 concentration and activity can also be related to ongoing inflammatory process, what was confirmed by the difference demonstrated only in the group of AP patients, in contrast to healthy subjects. A decrease in PON-1 activity may be secondary to increased levels of pro-inflammatory cytokines, which are responsible for downregulation of mRNA expression of PON-1, as it was demonstrated in earlier studies [42,43]. The pathomechanism of reduced PON-1 activities can be also associated with lipid metabolism disorders in $\mathrm{AP}$, what reflects particularly in HDL fraction [28,44]. Other researchers noted that inflammation and acute phase response are associated with a lower rate of lipoprotein synthesis in the liver [45]. In our study, increasing Castelli Index 1 during hospitalization of AP patients could be a result of disorders in HDL synthesis or low fat supply in diet, what also induced the decreased PON-1 activity. It was evidenced by negative correlation of Castelli Index 1 with PON-1(L) activity showed in the groups of non-smoking and smoking AP patients. A decrease in PON-1 activities can be a result of HDL dissociation from PON-1 molecule, its oxidation and increase in lipid peroxidation products concentrations under oxidative stress conditions as reported in other papers $[46,47]$. This thesis seems to be confirmed in our study by the strong correlations of PON-1 activities with HDL concentration and negative association of HDL and MDA concentrations in the groups of AP patients. Additionally, oxidative stress generated in the course of $\mathrm{AP}$ can be associated with escalation of 
inflammation, what was confirmed by the correlation of MDA or HNE-adducts with hsCRP concentrations showed in the group of non-smoking and smoking $\mathrm{AP}$ patients. It seems reasonable to search for reduction of this prooxidative and pro-inflammatory cascade by inclusion in the therapy medications with anti-inflammatory properties.

The results of this study showed the effect of smoking on PON-1 activities. Exposure to tobacco smoke xenobiotics was associated with the highest decrease in PON-1(P) activity, which most strongly correlated with MDA concentration in smokers. This result can indicate that $\mathrm{PON}-1(\mathrm{P})$ activity revealed high sensitivity to smoke xenobiotics as compared to the activity of other of the enzyme forms, what manifested in its inhibited activity in healthy smokers without accompanied decrease in PON-1 concentration. This effect can be explained by the interaction of reactive tobacco smoke xenobiotics (aldehydes, polycyclic aromatic hydrocarbons or heavy metals) with active center of PON-1 causing steric hindrance near region of the molecule critical for substrate binding, modification of thiol groups in active regions of PON-1 and inactivation of the entire enzyme [44,48-50].

A decreased activity of PON-1 in the course of $\mathrm{AP}$ is considered a marker of oxidative damage (11). Destruction of cell membrane and extracellular antioxidant defense activation can lead to disruption of the intracellular redox homeostasis, what was confirmed in this study by a decrease in GST- $\Pi$ activity as a result of tobaccos smoke exposure. Down-regulation of GST-п activity may be caused by blocking of the active center of the enzyme by smoke xenobiotics or the enzyme use up in detoxification processes. Sen et al. [51] showed that GST-ח activity can be reduced by $\mathrm{Cd}$, which intake into organism is mainly associated with tobacco smoke exposure. These findings were consistent with our study, in which the decrease in GST- $\Pi$ activity was strongly correlated with the increased $\mathrm{Cd}$ concentration in the blood of healthy smokers. GST-ח free radical scavenging potential seems to be weakened by oxidative stress produced in the course of AP, what was confirmed by negative correlation of this enzyme activity and MDA concentration in the blood of non-smoking AP.

\section{Conclusions}

- Increasing stay in the hospital was associated with worsening of lipids peroxidation markers and the parameters of lipid profile, in both non-smoking and smoking AP patients. It can indicate that the oxidative-inflammatory process is not extinguished.
- Oxidative stress generated in the course of AP can intensify the preexisting inflammation.

- The intensification of lipid peroxidation and damage of cellular membrane may be associated with a decrease in PON-1 activities into the blood of AP patients as a result of oxidative modification of HDL - an important molecule in proper PON-1 function.

- A decrease in PON-1 phosphotriesterase activity observed in smoking AP patients is an effect of the enzyme activity inhibition, rather than a decrease in PON-1 concentration. Inhibition of GST-ח activity can be a result of the interference of tobacco smoke xenobiotics with active center of this enzyme.

\section{Abbreviations}

AP: acute pancreatitis; $\mathrm{CH}$ : total cholesterol; GST-п: pi isoform of glutathione S-transferase; HDL: high density lipoproteins; HNE: hydroxynonenal; hsCRP: high-sensitivity C-reactive protein; MDA: malonylodialdehyde; oxLDL: oxidized low density lipoproteins; PON-1: paraoxonase-1; PON-1(A): arylesterase activity of paraoxonase-1; PON-1(L): lactonase activity of paraoxonase-1; PON-1(P): phosphotriesterase activity of paraoxonase-1.

\section{Acknowledgements}

This work was supported by the grant ST.D170.16.014 and STM.D170.17.006 from Wroclaw Medical University.

\section{Competing Interests}

The authors have declared that no competing interest exists.

\section{References}

1. Jamer T. Etiology of acute pancreatitis - underestimated problem in pediatrics. Dev Period Med. 2015; 3:341-6.

2. Kylänpää L, Rakonczay Z, O'Reilly DA. The clinical course of acute pancreatitis and the inflammatory mediators that drive it. Int J Inflamm. 2012; 2012:1-10.

3. Bhatia M, Brady M, Shokuhi S, Christmas S, Neoptolemos JP, Slavin J. Inflammatory mediators in acute pancreatitis. J Pathol. 2000;190:117-25.

4. $\mathrm{Yu} \mathrm{JH}$. Oxidative stress and inflammatory signaling in cerulein pancreatitis. World J Gastroenterol. 2014; 20:17324.

5. Kumar R, Bhatia M. Cells and mediators of inflammation in acute pancreatitis. Clin Anti-Inflamm Anti-Allergy Drugs. 2014; 1:11-23.

6. Barreto SG. How does cigarette smoking cause acute pancreatitis? Pancreatology. 2016; 16:157-63.

7. Edderkaoui M, Thrower E. Smoking and pancreatic disease. J Cancer Ther. 2013; 4:34-40.

8. Milnerowicz H, Ściskalska M, Dul M. Molecular mechanisms of the impact of smoke-oxidants. Exp Toxicol Pathol. 2015; 67:377-82.

9. Milnerowicz H, Ściskalska M, Dul M. Pro-inflammatory effects of metals in persons and animals exposed to tobacco smoke. J Trace Elem Med Biol. 2015; 29:1-10.

10. Levitzky YS, Guo C-Y, Rong J, Larson MG, Walter RE, Keaney JF, et al. Relation of smoking status to a panel of inflammatory markers: The Framingham offspring. Atherosclerosis. 2008; 201:217-24.

11. Tvarijonaviciute A, García-Martínez JD, Caldin M, Martínez-Subiela S, Tecles F, Pastor J, et al. Serum paraoxonase 1 (PON1) activity in acute pancreatitis of dogs. J Small Anim Pract. 2015; 56:67-71. 
12. van der Vaart $H$, Postma DS, Timens W, ten Hacken NHT. Acute effects of cigarette smoke on inflammation and oxidative stress: a review. Thorax. 2004; 59:713-21.

13. Aprioku JS. Pharmacology of free radicals and the impact of reactive oxygen species on the testis. J Reprod Infertil. 2013; 14:158-172.

14. V Ramana K. What is the role of lipid peroxidation product 2-hydroxynonenal in inflammation? Biochem Anal Biochem [Internet]. 2012. Revised 2018 Mar 16. https://www.omicsonline.org/what-is-the-role-of-lipid-peroxidationproduct-2-hydroxynonenal-in-inflammation-2161-1009.1000e105.php?aid=650

15. Novak F, Vavrova L, Kodydkova J, Novak F, Hynkova M, Zak A, et al. Decreased paraoxonase activity in critically ill patients with sepsis. Clin Exp Med. 2010; 10:21-5.

16. Aslan M, Horoz M, Sabuncu T, Celik H, Selek S. Serum paraoxonase enzyme activity and oxidative stress in obese subjects. Pol Arch Med Wewn. 2011; 121:181-6.

17. Mehdi MM, Rizvi SI. Human plasma paraoxonase 1 (PON1) arylesterase activity during aging: correlation with susceptibility of LDL oxidation. Arch Med Res. 2012; 43:438-43.

18. Bizoń A, Kepinska M, Snacki K, Milnerowicz H. The impact of environmental and biological factors on paraoxonase 1 and $\mathrm{v}$-glutamyltranspeptydase activities in the blood of smelters. Int J Environ Health Res. 2016; 26:222-38

19. Krzystek-Korpacka M, Patryn E, Hotowy K, Czapińska E, Majda J, Kustrzeba-Wójcicka I, et al. Paraoxonase (PON)-1 activity in overweight and obese children and adolescents: association with obesity-related inflammation and oxidative stress. Adv Clin Exp Med. 2013; 22:229-36.

20. Zhou C, Cao J, Shang L, Tong C, Hu H, Wang H, et al. Reduced paraoxonase 1 activity as a marker for severe coronary artery disease. Dis Markers. 2013; 35:97-103.

21. Ferretti G, Bacchetti T, Masciangelo S, Bicchiega V. HDL-paraoxonase and membrane lipid peroxidation: a comparison between healthy and obese subjects. Obesity. 2010; 18:1079-84.

22. Ceron JJ, Tecles F, Tvarijonaviciute A. Serum paraoxonase 1 (PON1) measurement: an update. BMC Vet Res. 2014; 10:74.

23. Erdem FH, Karatay S, Yildirim $\mathrm{K}$, Kiziltunc A. Evaluation of serum paraoxonase and arylesterase activities in ankylosing spondylitis patients. Clinics. 2010; 65:175-9.

24. Rodrigo L, Mackness B, Durrington PN, Hernandez A, Mackness MI Hydrolysis of platelet-activating factor by human serum paraoxonase. Biochem J. 2001; 354:1-7.

25. Conklin DJ, Haberzettl P, Prough RA, Bhatnagar A. Glutathione-S-transferase $P$ protects against endothelial dysfunction induced by exposure to tobacco smoke. Am J Physiol Heart Circ Physiol. 2009; 296:H1586-1597.

26. Aliya S, Reddanna P, Thyagaraju K. Does glutathione S-transferase Pi (GST-Pi) a marker protein for cancer? Mol Cell Biochem. 2003; 253:319-27.

27. Rau B. Pathophysiologic role of oxygen free radicals in acute pancreatitis. Ann Surg. 2000; 231:352-60.

28. Unal E, Uzun H, Kusaslan R, Dogan M, Genc H, Gunes P, et al Serum paraoxonase (a high-density lipoprotein-associated lipophilic antioxidant) activity and lipid profile in experimental acute pancreatitis. Pancreas. 2005; 31:84-7.

29. Vargas HO, Nunes SOV, Barbosa DS, Vargas MM, Cestari A, Dodd S, et al Castelli risk indexes 1 and 2 are higher in major depression but other characteristics of the metabolic syndrome are not specific to mood disorders. Life Sci. 2014; 102:65-71.

30. Eckerson HW, Romson J, Wyte C, La Du BN. The human serum paraoxonase polymorphism: identification of phenotypes by their response to salts. Am J Hum Genet. 1983; 35:214-27.

31. Lixandru D, Mohora M, Coman A, Stoian I, van Gils C, Aerts P, et al. Diet and paraoxonase 1 enzymatic activity in diabetic foot patients from Romania and Belgium: favorable association of high flavonoid dietary intake with arylesterase activity. Ann Nutr Metab. 2010; 56:294-301.

32. Kataoka M, Honda K, Shimizu S. 3,4-Dihydrocoumarin hydrolase with haloperoxidase activity from Acinetobacter calcoaceticus F46. Eur J Biochem. 2000; 267:3-10.

33. Habig WH, Pabst MJ, Jakoby WB. Glutathione S-transferases. The first enzymatic step in mercapturic acid formation. J Biol Chem. 1974; 249:7130-9.

34. Armstrong JA, Cash N, Soares PMG, Souza MHLP, Sutton R, Criddle DN. Oxidative stress in acute pancreatitis: lost in translation? Free Radic Res. 2013; 47:917-33.

35. Huang Y, Wu Z, Riwanto M, Gao S, Levison BS, Gu X, et al. Myeloperoxidase, paraoxonase-1, and HDL form a functional ternary complex. J Clin Invest. 2013; 123:3815-28.

36. Sztanek F, Seres I, Harangi M, Locsey L, Padra J, Paragh GJR, et al. Decreased paraoxonase 1 (PON1) lactonase activity in hemodialyzed and renal transplanted patients. A novel cardiovascular biomarker in end-stage renal disease. Nephrol Dial Transplant. 2012; 27:2866-72.

37. Aviram M, Rosenblat M, Bisgaier CL, Newton RS, Primo-Parmo SL, La Du BN. Paraoxonase inhibits high-density lipoprotein oxidation and preserves its functions. A possible peroxidative role for paraoxonase. J Clin Invest. 1998; 101:1581-90

38. Nguyen SD, Sok D-E. Oxidative inactivation of paraoxonase1, an antioxidant protein and its effect on antioxidant action. Free Radic Res. 2003; 37:1319-30.
39. Franco-Pons N, Marsillach J, Joven J, Camps J, Closa D. Serum paraoxonase undergoes inhibition and proteolysis during experimental acute pancreatitis. J Gastrointest Surg. 2008; 12:891-9.

40. Pizzimenti S, Ciamporcero E, Daga M, Pettazzoni P, Arcaro A, Cetrangolo G, et al. Interaction of aldehydes derived from lipid peroxidation and membrane proteins. Front Physiol [Internet]. 2013. Revised 2018 Apr 3. http://journal.frontiersin.org/article/10.3389/fphys.2013.00242/abstract

41. Kumar D, Rizvi SI. Age-dependent paraoxonase 1 (PON1) activity and LDL oxidation in Wistar rats during their entire lifespan. Sci World J. 2014; 2014:1-6.

42. Kumon $\mathrm{Y}$, Nakauchi $\mathrm{Y}$, Suehiro $\mathrm{T}$, Shiinoki $\mathrm{T}$, Tanimoto $\mathrm{N}$, Inoue $\mathrm{M}$, et al Proinflammatory cytokines but not acute phase serum amyloid A or C-reactive protein, downregulate paraoxonase 1 (Pon1) expression by Hepg2 cells. Amyloid. 2002; 9:160-4

43. Hussein O, Zidan J, Abu Jabal K, Shams I, Szvalb S, Grozovski M, et al. Paraoxonase activity and expression is modulated by therapeutics in experimental rat nonalcoholic fatty liver disease. Int J Hepatol. 2012; 2012:1-9.

44. Haj Mouhamed D, Ezzaher A, Mechri A, Neffati F, Omezzine A, Bouslama A, et al. Effect of cigarette smoking on paraoxonase 1 activity according to PON1 L55M and PON1 Q192R gene polymorphisms. Environ Health Prev Med. 2012; 17:316-21.

45. Khan J, Nordback I, Sand J. Serum lipid levels are associated with the severity of acute pancreatitis. Digestion. 2013; 87:223-8.

46. Savu O, Serafinceanu C, Grajdeanu IV, Iosif L, Gaman L, Stoian I. Paraoxonase lactonase activity, inflammation and antioxidant status in plasma of patients with type 1 diabetes mellitus. J Int Med Res. 2014; 42:523-9.

47. Salazar J, Olivar LC, Ramos E, Chávez-Castillo M, Rojas J, Bermúdez V. Dysfunctional high-density lipoprotein: an innovative target for proteomics and lipidomics. Cholesterol. 2015; 2015:1-22

48. Milnerowicz H, Kowalska K, Socha E. Paraoxonase activity as a marker of exposure to xenobiotics in tobacco smoke. Int J Toxicol. 2015; 34:224-32.

49. Ciumarnean L., Milaciu MV., Macarie AE., Sampelean DP., Achimas-Cadariu A.: Non-genetic factors influencing serum PON1 levels. Hum Vet Med. 2014; 6:20.

50. Pollack AZ, Sjaarda L, Ahrens KA, Mumford SL, Browne RW Wactawski-Wende J, et al. Association of cadmium, lead and mercury with paraoxonase 1 activity in women. Meliker J, editor. PLoS ONE. 2014; 9:e92152.

51. Sen A, Semiz A. Effects of metals and detergents on biotransformation and detoxification enzymes of leaping mullet (Liza saliens). Ecotoxicol Environ Saf. 2007; 68:405-11 